Med Princ Pract 2011;20:584

DOI: $10.1159 / 000330033$

\section{Primary Prevention for Cardiovascular Diseases: Can Statins Replace Aspirin?}

\author{
Muhammad Abdul Hadi ${ }^{\mathrm{a}}$ Long Chiau Ming ${ }^{\mathrm{b}}$, Ahmed Awaisuc

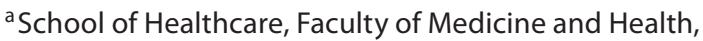 \\ University of Leeds, Leeds, UK; ${ }^{\text {b }}$ Faculty of Pharmacy, Universiti \\ Teknologi MARA, Puncak Alam, Malaysia; ' College of Pharmacy, \\ University of Qatar, Doha, Qatar
}

Being the leading cause of morbidity and mortality, cardiovascular diseases (CVDs) have become a major public health concern globally. Over the past two decades, lifestyle modification (low-fat diet, smoking cessation, increased physical activity, weight management) together with aspirin have been the cornerstone for both primary and secondary prevention for CVDs. However, new clinical trials and meta-analyses have called into question the effectiveness of aspirin in primary prevention [1], even among patients with diabetes $[2,3]$, a disease condition considered as coronary heart disease equivalent. Interestingly, a longitudinal observational study reported an increased CVD risk associated with lowdose aspirin for primary prevention among Chinese patients with type 2 diabetes [4]. The authors further reported a hazard ratio of $2.2(95 \% \mathrm{CI}=1.53-3.15, \mathrm{p}<0.001)$ for gastrointestinal bleeding and of $1.71(95 \% \mathrm{CI}=1.00-2.95, \mathrm{p}=0.051)$ for hemorrhagic stroke associated with the use of aspirin [4]. On the other hand, recent meta-analyses have strengthened the evidence on the effectiveness of HMG-CoA reductase inhibitors (statins) in primary prevention $[5,6]$. A significant risk reduction of $12 \%$ in all-cause mortality, $30 \%$ in major coronary events and $19 \%$ in major cerebrovascular events was reported to be associated with the use of statins [5]. Furthermore, the use of statins was not associated with an increased risk of cancer [5]. However, another meta-analysis reported a $9 \%$ increase in risk of incident diabetes (odds ratio = 1.09 ; $95 \% \mathrm{CI}=1.02-1.17$ ) associated with the use of statins, with the highest risk among elderly patients [7]. The authors considered the risk of development of diabetes to be low in absolute terms and when compared with reduction in coronary events in patients with moderate to high cardiovascular risk or existing cardiovascular disease, but statins should be used with caution in patients with low cardiovascular risk [7]. Although substantial data are available to support the use of statins in primary prevention, cost-effectiveness is yet to be demonstrated.

It has been argued that perhaps the currently recommended low dose of aspirin is responsible for its lack of effectiveness and a dose increase to $160 \mathrm{mg}$ is advocated [8]. However, increased risk of hemorrhage associated with high dose of aspirin should not be overlooked. At present, clinical research has failed to clearly answer key questions on the safety of long-term use of statins and safe and optimum dose of aspirin. No data on the direct comparison of aspirin and statins are available.

Well-designed head-to-head clinical trials of aspirin and statins are required to document the superiority of either of these agents in the primary prevention of CVDs. Until results of such trials become available, it will be inappropriate either to replace aspirin with statin or to increase the dose of aspirin in the primary prevention of CVDs. Until then, low-dose aspirin (80 $\mathrm{mg}$ ) should continue to enjoy its long-term monopoly as the drug of mainstay in the primary prevention of CVD; nevertheless, careful patient selection should be made based on age, gender and $\mathrm{CV}$ risk.

\section{References}

1 Antithrombotic Trialists' (ATT) Collaboration: Aspirin in the primary and secondary prevention of vascular disease: collaborative meta-analysis of individual participant data from randomized trials. Lancet 2009;373:1849-1860.

-2 Ogawa H, Nakayama M, Morimoto T, Uemura S, Kanauchi M, Doi N, Jinnouchi H, Sugiyama S, Saito Y: Low-dose aspirin for primary prevention of atherosclerotic events in patients with type 2 diabetes. JAMA 2008;300:2134-2141.

-3 De Berardis G, Sacco M, Strippoli GF, Pellegrini F, Graziano G, Tognoni G, Nicolucci A: Aspirin for primary prevention of cardiovascular events in people with diabetes: meta-analysis of randomized controlled trials. BMJ 2009;339:b4531.

4 Leung WY, So WY, Stewart D, Lui A, Tong PC, Ko GT, Kong AP, Ma RC, Chan FK, Yang X, Chiang SC, Chan JC: Lack of benefits for prevention of cardiovascular disease with aspirin therapy in type 2 diabetic patients - A longitudinal observational study. Cardiovasc Diabetol 2009;8:57.

5 Brugts JJ, Yetgin T, Hoeks SE, Gotto AM, Shepherd J, Westendorp RG, de Craen AJ, Knopp RH, Nakamura H, Ridker P, van Domburg R, Deckers JW: The benefits of statins in people without established cardiovascular disease but with cardiovascular risk factors: meta-analysis of randomised controlled trials. BMJ 2009;338:b2376.

-6 Edward JM, Beth R, Ping W, Philip JD, Paul A, Dan P: Primary prevention of cardiovascular mortality and events with statin treatments. J Am Coll Cardiol 2008;52:1769-1781.

7 Sattar N, Preiss D, Murray DM, Welsh P, Buckley BM, de Craen AJ, Seshasai SR, McMurray JJ, Freeman DJ, Jukema JW, Macfarlane PW, Packard CJ, Stott DJ, Westendorp RG, Shepherd J, Davis BR, Pressel SL, Marchioli R, Marfisi RM, Maggioni AP, Tavazzi L, Tognoni G, Kjekshus J, Pedersen TR, Cook TJ, Gotto AM, Clearfield MB, Downs JR, Nakamura H, Ohashi Y, Mizuno K, Ray KK, Ford I: Statins and risk of incident diabetes: a collaborative meta-analysis of randomised statin trials. Lancet 2010;375:735-742.

8 Dalen JE: Aspirin for the primary prevention of stroke and myocardial infarction: ineffective or wrong dose? Am J Med 2010;123:101-102.

\section{KARGER}

Fax +4161306 1234

E-Mail karger@karger.ch

www.karger.com (c) 2011 S. Karger AG, Basel

1011-7571/11/0206-0584\$38.00/0

Accessible online at:

www.karger.com/mpp
Muhammad Abdul Hadi, BPharm, MPharm (Clinical)

School of Healthcare, Faculty of Medicine and Health

University of Leeds

Leeds LS2 9UT (UK)

Tel. +44 757910 4704, E-Mail abdulhadi83@ gmail.com 